\title{
Creep of an Oxidation Resistant Coated Mo-9Si-8B Alloy
}

\section{Camelia Gombola ${ }^{1}$, Daniel Schliephake ${ }^{2}$, Martin Heilmaier ${ }^{1}$, John H. Perepezko $^{3}$}

${ }^{1}$ Karlsruhe Institute of Technology (KIT) Institute for Applied Materials, Engelbert-Arnold-Str. 4, 76131 Karlsruhe, Germany, ${ }^{2}$ Monash University, Materials Science and Engineering, Notting Hill, VIC 3168, Australia, ${ }^{3}$ University of Wisconsin - Madison, Department of Materials Science and Engineering, 1509 University Avenue, Madison, WI 53706, USA

Keywords: High-temperature materials; Mo-Si-B alloys; Pack cementation; Oxidation-resistant coating; creep

\section{Abstract}

In order to evaluate the impact of an oxidation resistant coating on the structural performance of a Mo-9Si-8B alloy tensile creep experiments were conducted at $1200{ }^{\circ} \mathrm{C}$. After a plastic strain of $6 \%$ the creep rates of the coated samples compared favorably with the reported values for uncoated samples. Moreover, the coating structure was maintained during creep deformation and the coating exhibited a self-healing capability.

Introduction

The current paradigm of nickel-based superalloys has approached the very limits of hightemperature strength and stability, often operating at $0.9 \mathrm{~T}_{\mathrm{m}}$, of the incipient melting temperature [1]. In order to realize an increase in hot section intake temperatures alternative material systems must be explored. The Mo-Si-B alloy system is a promising candidate due to a number of exceptional properties possessed by the multiphase microstructures. For example, at $1200{ }^{\circ} \mathrm{C}$ the flow stress at $4 \%$ strain in a three phase Mo-9Si-8B alloy is more than twice that for the commercial TZM alloy [2]. In earlier studies, oxidation-prone molybdenum was shown to be protected from oxidizing environments by the $\mathrm{Mo}-\mathrm{Si}-\mathrm{B}$ based coating structure to temperatures as high as $1600{ }^{\circ} \mathrm{C}$ [3]. In order for such a coating to be implemented into a gas turbine engine, it must demonstrate stability and robustness in a wide variety of environmental and operation conditions.

Numerous studies on high temperature oxidation behavior in $\mathrm{Mo}-\mathrm{Si}-\mathrm{B}$ alloys reveal that the alloy compositions with the best performance do not have satisfactory mechanical properties (notably low temperature ductility and fracture toughness) due to the high volume fraction of silicide phases needed for the oxidation resistance [4]. Similarly, alloy compositions with satisfactory mechanical properties usually exhibit poor oxidation resistance due to the continuous Moss phase [5]. One strategy to address this dilemma is to apply an oxidation resistant coating. A successful coating has been developed based upon a co-deposition of B and Si by pack cementation that exhibits thermodynamic and mechanical compatibility and self-healing [6]. The coating has been 
demonstrated to provide a robust environmental resistance to attack by oxidation, CMAS, hot corrosion by molten salt and water vapor [3]. Besides the environmental resistance it is important to assess the influence of the coating on the mechanical behavior. In this work it is demonstrated that the high temperature creep performance of a Mo-9Si-8B alloy is essentially unaffected by the coating, proving the protective capability of the coating under application relevant conditions with superimposed plastic deformation.

\section{Experimental Procedures}

The Mo-9Si-8B alloy (in at.\%) was manufactured from elemental powders Mo, Si and B with purities of $99.95 \%, 99.9 \%$ and $98 \%$ respectively. Mechanical alloying was carried out using a planetary ball mill (Retsch PM 400) with WC balls, a powder to ball ratio of 1:12 and a speed of $200 \mathrm{rpm}$ [5]. Compaction was carried out using the field assisted sintering technique (FAST) at $1600{ }^{\circ} \mathrm{C}$ and $50 \mathrm{MPa}$ for hold times of $15 \mathrm{~min}$. As a result, buttons with a diameter of $50 \mathrm{~mm}$ and a height of $10 \mathrm{~mm}$ and a residual porosity of $<2 \%$ were produced [7].

After homogenization treatment at $1600{ }^{\circ} \mathrm{C}$ for $100 \mathrm{~h}$, dogbone shaped tensile samples with a total length of $35 \mathrm{~mm}$, a gage length of $15 \mathrm{~mm}$ and a square cross-section of $3 \times 4 \mathrm{~mm}^{2}$ were manufactured from above buttons by EDM (see insert in Fig. 3). Prior to pack cementation the gage section of these samples was ground to a 2500 grit finish. The tensile samples were then embedded in a powder mixture consisting of $62.5 \mathrm{wt} . \% \mathrm{Al}_{2} \mathrm{O}_{3}, 35 \mathrm{wt} \%$ Si and $\mathrm{B}$ mixture $(\mathrm{Si} / \mathrm{B}=$ 35/1) and $2.5 \mathrm{wt} \% \mathrm{NaF}$ for pack cementation in an $\mathrm{Ar}$ atmosphere at $1000{ }^{\circ} \mathrm{C}$ for $40 \mathrm{~h}$ to codeposit the $\mathrm{Si}$ and $\mathrm{B}$. A detailed description of the pack cementation process can be found elsewhere $[8,9]$.

Tensile creep tests were on the one hand carried out under constant true stresses at $1200{ }^{\circ} \mathrm{C}$ in a Zwick universal testing device equipped with a Maytec vacuum furnace $\left(<10^{-4} \mathrm{~Pa}\right)$. The creep strain as by inductive displacement transducers attached to the sample gage section was continuously monitored to test that the coating does not affect the creep behavior. For further details see [10]. On the other hand, further creep tests were performed in air in order to verify the adhesion and self-healing capability of the coating.

\section{Results}

The initial coating structure after pack cementation is displayed in Fig. 1a where (from left to right) an outer amorphous borosilica layer is in contact with a $\mathrm{MoSi}_{2}$ layer which in turn is in contact with a mixed $\mathrm{MoB}$ and $\mathrm{Mo}_{5} \mathrm{SiB}_{2}\left(\mathrm{~T}_{2}\right)$ layer before reaching the three phase $\mathrm{Mo}_{\text {ss }}+\mathrm{Mo}_{3} \mathrm{Si}+\mathrm{T}_{2}$ substrate. After conditioning at $1400{ }^{\circ} \mathrm{C}$ for $10 \mathrm{~h}$ in air the coating structure evolves into the structure shown in Fig. $1 \mathrm{~b}$ where the top and bottom portion of the MoSi $\mathrm{i}_{2}$ layer converts to $\mathrm{Mo}_{5} \mathrm{Si}_{3}$ which is followed by a MoB/T 2 layer before reaching the substrate. Exposure of samples with this coating at $1700{ }^{\circ} \mathrm{C}$ for periods of 25 hours (without mechanical loading) indicated a negligible mass change of less than $1.7 \mathrm{mg} / \mathrm{cm}^{2}[11]$. 

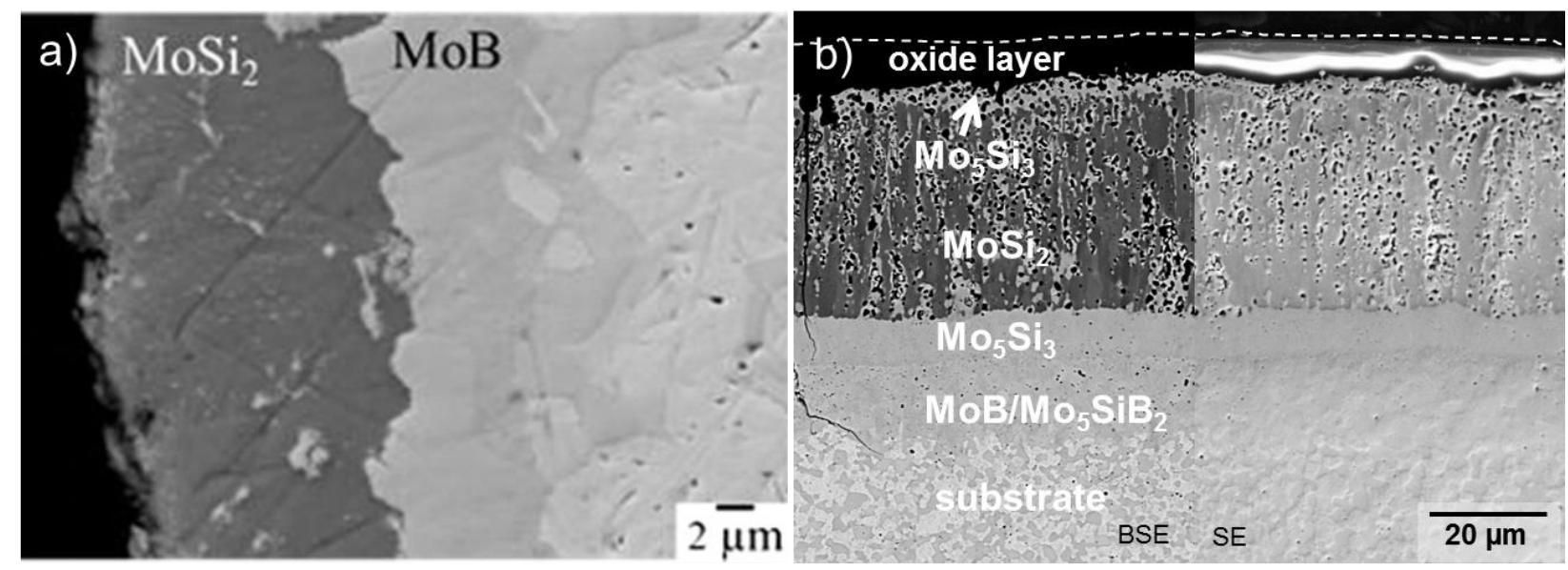

Fig. 1 a) BSE-micrograph of the as-packed sample [3], b) BSE-micrograph left and SEmicrograph right of the conditioned coated Mo-9Si-8B sample

Following exposure at $1200{ }^{\circ} \mathrm{C}$ in air and under an applied creep stress of $50 \mathrm{MPa}$ the sample exhibited a full retention of the coating after $6 \%$ plastic strain as shown in plan view in Fig. $2 a$ and in cross section in Fig. 2b. There was no evidence for coating spallation or oxidation of the substrate. Some crack development was detected normal to the tensile direction (Fig. 2b) but it is evident that the borosilica was able to form and flow into the cracks as a self-healing process (white arrows in Fig. 2b II). In essence the same observations were made for creep tested samples at $1200{ }^{\circ} \mathrm{C}$ under a stress of $100 \mathrm{MPa}$.
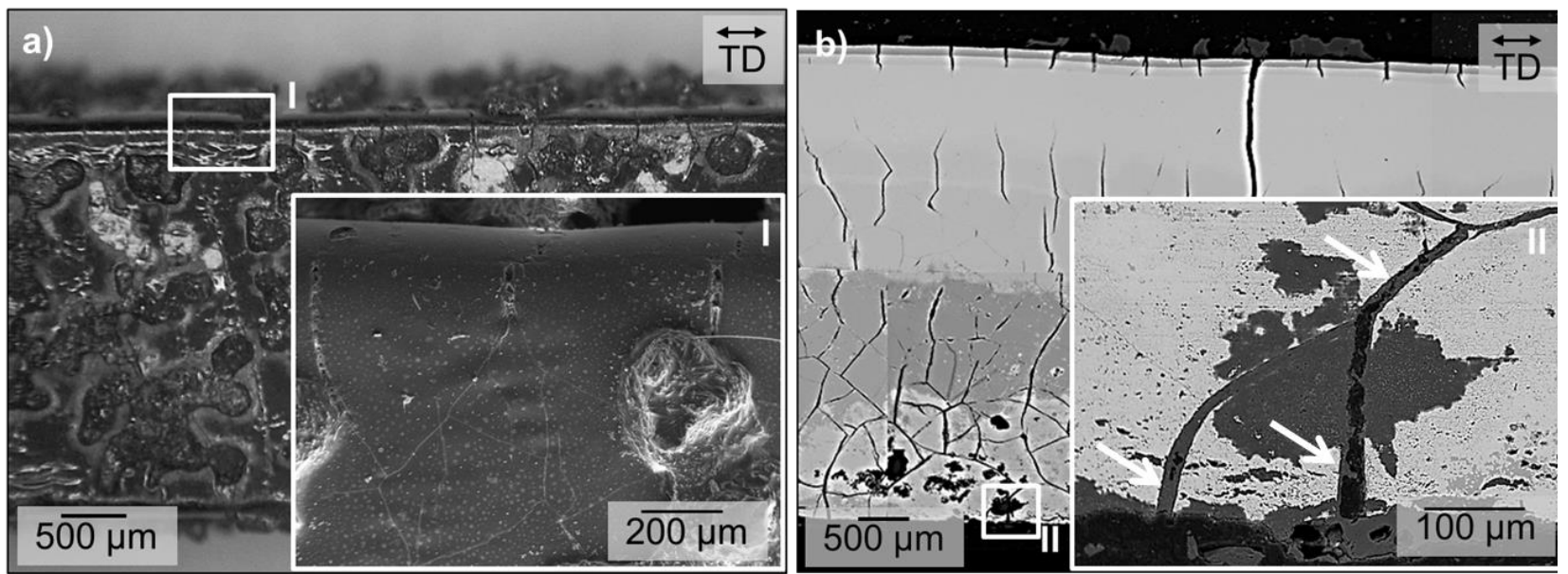

Fig. 2 a) In plan view of coated sample surface after $6 \%$ plastic strain, b) cross section of coated sample after $6 \%$ plastic strain illustrating the flow of borosilica to fill cracks (TD refers to tensile direction) 


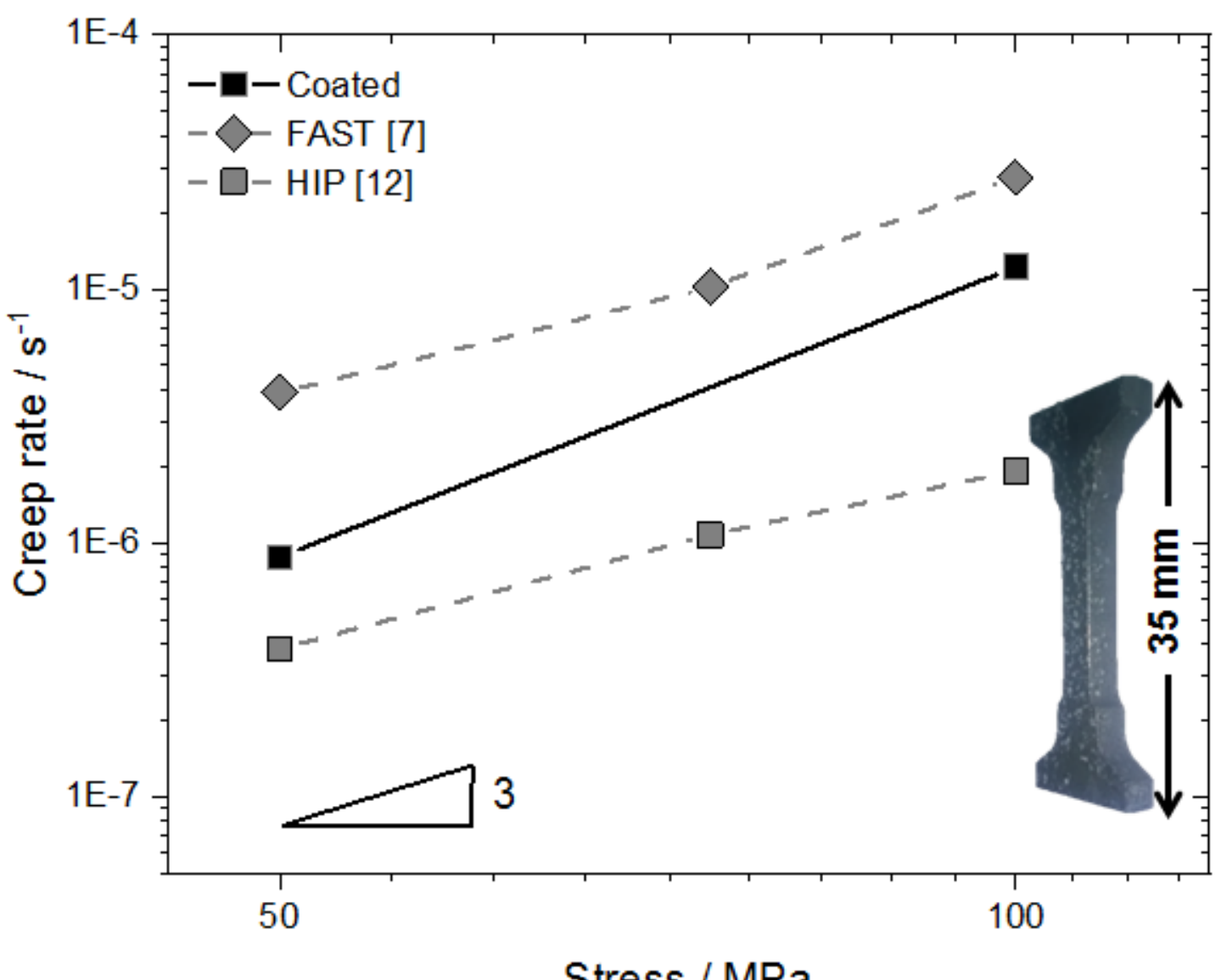

Stress / MPa

Fig. 3) Double logarithmic plot of the minimum strain rate vs. applied stress at $1200{ }^{\circ} \mathrm{C}$ for Mo9Si-8B alloys with different grain sizes. The grain size for the uncoated FAST sample is $0.75 \mu \mathrm{m}$ [7] and that for the uncoated HIP sample is $1.5 \mu \mathrm{m}$ [12] while that for the coated sample has an intermediate value of about $1.3 \mu \mathrm{m}$.

The minimum creep rates for the coated samples were compiled with literature results obtained on uncoated material and are plotted in Fig. 3 versus the applied creep stress. Two conclusions can be drawn from this comparison: (i) as discussed in [7] for a series of Mo-9Si-8B alloys with different $\mathrm{Zr}$ additions, a clear tendency for increased creep rates with decreasing grain size is noted. This was explained in [7] by the increased contribution of grain boundary sliding processes and our coated samples fit very well into this trend; (ii) no obvious impact of the additional coating on the course of the minimum creep rates is found which expresses itself in the similar stress exponents ranging between 2.3 and 3.7. This supports the above observations in that the coating is well adherent and obviously able to protect the underlying substrate well. 


\section{Conclusions}

The effect of an oxidation resistant Mo-Si-B based coating on the deformation of a Mo-9Si-8B alloy was evaluated during tensile creep experiments at $1200{ }^{\circ} \mathrm{C}$. The observed creep rates for coated samples at stresses between 50 and $100 \mathrm{MPa}$ are consistent with the reported values for uncoated samples demonstrating that the coating had a negligible effect on the creep behavior. At a plastic strain of $6 \%$ some cracking was observed normal to the tensile direction, but the cracks were filled by flowing borosilica glass indicating a self-healing capability. The coating structure was maintained during creep deformation.

Acknowledgement

The financial support of Deutsche Forschungsgemeinschaft (DFG), grant no. HE 1872/33-1, and by Karlsruhe House of Young Scientists (KYHS) is gratefully acknowledged. This work was partly carried out with the support of the Karlsruhe Nano Micro Facility (KNMF, www.knmf.kit.edu), a Helmholtz Research Infrastructure at Karlsruhe Institute of Technology (KIT, http://www.kit.edu). JHP gratefully acknowledges the support of the ONR (N00014-17-12575).

References

[1] J.H. Perepezko, The hotter the engine, the better, Science 326 (2009) 5956-5957, https://doi.org/10.1126/science.1179327.

[2] A.P. Alur, N. Chollacoop, K.S. Kumar, High-temperature compression behavior of MoSi-B alloys, Acta Materialia 52 (2004) 5571-5587, https://doi.org/10.1016/j.actamat.2004.08.035.

[3] J.H. Perepezko, R. Sakidja, Extended functionality of environmentally-resistant Mo-SiB-based coatings, JOM 65 (2013) 307-317, https:Ildoi.org\10.1007/s11837-012-0520-0.

[4] J.H. Schneibel, R.O. Ritchie, J.J. Kruzic, P.F. Tortorelli, Optimization of Mo-Si-B intermetallic alloys, Metall. Mater. Trans. A36 (2005) 525-531, https://doi.org/10.1007/s11661-005-0166-4.

[5] M. Krüger, S. Franz, H. Saage, M. Heilmaier, J.H. Schneibel, P. Jéhanno, M. Böning, H. Kestler, Mechanically alloyed Mo-Si-B alloys with a continuous $\alpha$-Mo matrix and improved mechanical properties, Intermetallics 16 (2008) 933-941, https://doi.org/10.1016/j.intermet.2008.04.015.

[6] J.H. Perepezko, Surface engineering of Mo-base alloys for elevated-temperature environmental resistance, Ann. Rev. Mater. Res. 45 (2015) 519-542, https://doi.org/10.1146/annurev-matsci-070214-020959. 
[7] C. Hochmuth, D. Schliephake, R. Völkl, M. Heilmaier, U. Glatzel: Influence of zirconium content on microstructure and creep properties of Mo-9Si-8B alloys, Intermetallics 48 (2014) 3-9, https://doi.org/10.1016/j.intermet.2013.08.017.

[8] A. Lange, M. Heilmaier, T.A. Sossamann, J.H. Perepezko, Oxidation behavior of packcemented Si-B oxidation protection coatings for Mo-Si-B alloys at $1300^{\circ} \mathrm{C}$, Surf. Coat. Tech. 266 (2015) 57-63, https://doi.org/10.1016/j.surfcoat.2015.02.015.

[9] D. Schliephake, C. Gombola, A. Kauffmann, M. Heilmaier, J.H. Perepezko, Enhanced oxidation resistance of Mo-Si-B-Ti alloys by pack cementation, Oxid. Met. 88 (2017) 267-277, https://doi.org/10.1007/s11085-017-9730-8.

[10] D. Schliephake, M.A. Azim, K. v. Klinski-Wetzel, B. Gorr, H.-J. Christ, H. Bei, E. P. George, M. Heilmaier, High-Temperature creep and oxidation behavior of Mo-Si-B alloys with high Ti contents, Metall. Mater. Trans. 45A (2014) 1102-1111, https://doi.org/10.1007/s11661-013-1944-z.

[11] J.H. Perepezko, R. Sakidja, Oxidation resistant coatings for ultra-high temperature refractory Mo-based alloys, JOM 62 (2010) 13-19, https://doi.org/10.1007/s11837-0100148-x.

[12] M. Krüger, D. Schliephake, P. Jain, K.S. Kumar, G. Schumacher, M. Heilmaier, Effects of $\mathrm{Zr}$ additions on the microstructure and the mechanical behavior of PM Mo-Si-B alloys, JOM 65 (2013) 301-306, https://doi.org/10.1007/s11837-012-0475-1. 